directly, or indirectly through the thyroid, as an anti-toxin or to its effect as a stimulant to cellular metabolism.

If we can depend upon results such as those given above we shali materially better the prognosis of chorio-retinal oedema, and the effects obtained in these cases and in many others of different type, justify careful investigation of the treatment.

\title{
A CASE OF CONGENITAL GLAUCOMA OF UNUSUAL TYPE
}

BY

\author{
W. G. LaWs \\ NOTTINGHAM
}

THE account of a peculiar case of glaucoma in the BRITISH JournaL of. Ophthalmology for February reminds me of one presenting in some respects similar, and at all events interesting, features, a short note of which may be worth publishing.

M.P. was a girl, aged 15 years, when I saw her in March, 1923. Her right eye had a semi-dilated pupil, surrounded by a ring of uveal pigment; the pupil showed no reaction to light but acted consensually. The fundus presented a striking appearance. The disc was deeply cupped ( $\approx \mathrm{D}$. to $8 \mathrm{D}$.), the retinal veins were enormously distended, the arteries also considerably larger than normal. Tension was about +1 ; the field of vision a small oval $10^{\circ}$ in horizontal, $8^{\circ}$ in vertical diameter, including the macula, and reaching to the blind spot. Central vision was $6 / 12$ (partly). The left eye, except for a small error of refraction, was quite normal.

Some months later Sir R. Cruise saw her. He wrote: "The pupillary and retinal conditions are most striking and interesting, and I thought that at about 11 o'clock the root of the iris looked as if it was adherent far back to the cornea-probably a congenital condition which by occupying sufficient of the circumference of the base of the iris would account for the glaucoma."

Operation (Aug., 1923) seemed to confirm this view. On making a "small flap" at the upper margin of the cornea the point of the keratome as it entered the anterior chamber engaged at once in some filmy tissue lying between the cornea and the iris; as it could not be disengaged the incision was enlarged by small sideway movements instead of by pushing the keratome onwards. When the vertical scleral cuts were made the bleeding was unusually free and persistent. A tendency to iris prolapse necessitated a small iridectomy, and the bleeding was again extremely free. A fort- 
night after operation it was noted that the turgidity of the fundus veins was. less.

For about three months after operation there were occasional attacks of pain round the right eye, but these gradually ceased. When last seen (Dec., 1925) the retinal vessels were of not more than normal size; the depth of the cup was $5.5 \mathrm{D}$. to $6 \mathrm{D}$.; central vision was $6 / 6$ (partly); the area of the field of vision was the same as before. A feature of the case which was not obviously explicable was that the right eye was slightly $\left({ }^{\prime \prime}\right)$ more prominent than the left. It remained so after operation.

No history could be obtained which enabled one to date the onset of the glaucoma. The outgrowth of uvea through the pupil suggested that it had been present for at least a couple of years. It seems possible that it had something to do with the onset of puberty.

\section{BILATERAL CYSTS OF THE CORNEA}

BY

L. Webster Fox, M.D., LL.D.

PHILADELPHIA

CySTs of the cornea must be very rare indeed, since a careful search of the tabulated and indexed records in ophthalmology brings to our attention only the case reported by de Schweinitz and Crampton in the Ophthalmic Record, Vol. XX, page 42, 1911. There are other case reports of cysts of the cornea secondary to direct injury recorded by Collins, Schieck, Czermak, Gruening, Tertsch, Augstein, Clausnizer and Tirumurti, but only that reported by the first-mentioned observer corresponds with the case here under observation. Even including all of these cases the condition is by no means commonplace. In the American Journal of Ophthalmology among the abstracts there is a note upon this subject by Fileti, published in the Ann. di Ottal. e Clin. Ocul., Vol. 53, p. 696, 1925, concerning the bibliography of the condition. According to this writer only twenty cases are reported in literature and of these only eleven have included pathological findings. Also in this paper he describes a case seen by himself in which the condition followed an inflammatory affection of the cornea. He excised the cyst in one instance, but was unable to demonstrate any connection with the anterior chamber. The vision was reduced to $1 / 60$ in one eye and $1 / 14$ in the other and was not improved by operation. These cysts were true cysts and lined with endothelium. The cyst in our case was in reality a separation of the lamellae of the cornea. 